\title{
Solid State structure of a novel asymmetric azine: A search for new materials with NLO properties
}

\author{
Wesley F. Vaz ${ }^{1,2}$, Jean M. F. Custodio ${ }^{1}$, Gilberto L. B. de Aquino ${ }^{1}$ and Hamilton B. Napolitano ${ }^{1}$
}

${ }^{1}$ Instituto Federal de Educação, Ciência e Tecnologia de Mato Grosso, 78455-000, Lucas do Rio Verde, MT, Brazil ${ }^{2}$ Ciências Exatas e Tecnológicas, Universidade Estadual de Goiás, 459, 75001-970, Anápolis, GO, Brazil.

A broad analysis of new azine (1E,2E)-1-(4-ethoxybenzylidene)-2-(1-(4-ethoxybenzylidene)-2-(1(4-nitrophenyl)ethylidene)hydrazine [NPT-HI], $\mathrm{C}_{17} \mathrm{H}_{17} \mathrm{~N}_{3} \mathrm{O}_{3}$, is reported throughout a single crystal X-ray diffraction, spectroscopic investigations and DFT calculations. The results of ab initio calculations on (hyper)polarizabilities derived from iterative process confirmed this crystal as a good candidate for photonic devices and optical power applications. The asymmetric azine NPT-HI crystallizes in the centrosymmetric space group $\mathrm{P} \overline{1}$ and has an almost planar conformation confirmed by C3-C4-C7-C8 dihedral angle $\left(-18.5^{\circ}\right)$, involving the methyl group. In addition, the non-linearity of the compound is evaluated by the more discrepant dihedral angles that are: C2-C1-N1-O1 $\left(10.3^{\circ}\right), \mathrm{C} 6-\mathrm{C} 1-\mathrm{N} 1-\mathrm{O} 1\left(170.2^{\circ}\right)$, C2-C1-N1-O2 $\left(169.59^{\circ}\right)$, C6-C1-N1-O2 $\left(9.9^{\circ}\right)$, C7-N2-N3-C9 $\left(-165.17^{\circ}\right)$, C3-C4-C7-N2 $\left(161.16^{\circ}\right)$, C5-C4C7-N2 $\left(-19.1^{\circ}\right)$, C3-C4-C7-C8 $\left(-18.5^{\circ}\right)$ and C5-C4-C7-C8 $\left(161.3^{\circ}\right)$. When compared to the bond lengths involved in a conjugated system $(\approx 1.38 \AA)$, the $\mathrm{N} 1-\mathrm{C} 1$ bond has a greater value $(1.465 \AA)$ indicating nonexistence of electron transfer between the nitro group and adjacent phenyl ring. The crystal packing is stabilized by $\mathrm{C}-\mathrm{H} \cdots \mathrm{O}$ interactions (Fig. 1) and is constituted of the stack of two-dimensional layer stabilized by such interactions. Each layer is formed of dimers stabilized by $\mathrm{C} 15-\mathrm{H} 15 \cdots \mathrm{O} 2$ and C9$\mathrm{H} 9 \cdots \mathrm{O} 2$ interactions, which are linked by $\mathrm{C} 14-\mathrm{H} 14 \cdots \mathrm{O} 1$. Additionally, the $\mathrm{C} 15-\mathrm{H} 15 \cdots \mathrm{O} 2$ interaction is shorter than $\mathrm{C} 9-\mathrm{H} 9 \cdots \mathrm{O} 2$; it is consistent by the observed difference between the distances of both interactions (2.455 $\AA$ and $2.608 \AA$ ). Moreover, the analysis of the Hirshfeld surface of indexed form indicates the packing is also stabilized by $\mathrm{CH}^{\cdots} \pi$ interactions on a centrosymmetric dimmer. Such interactions are very important in the structural analysis of NPT-HI since the $\mathrm{C}-\mathrm{H} \cdots \mathrm{O}$ interactions only form a two-dimensional layer that interact throughout $\mathrm{C}-\mathrm{H} \cdots \pi$ interactions. The layers are stacked through C17-H17A $\cdots \mathrm{Cg} 2$ dimmer interaction, with a distance $2.913 \AA$ between $\mathrm{H} 17 \mathrm{~A}-\mathrm{Cg} 2$. The fingerprint contains different information about the crystal packing of NPT-HI. Being an organic molecule filled with hydrogen atoms, the $\mathrm{H} \cdots \mathrm{H}$ contacts constitute a high percentage in fingerprints $(42.9 \%)$. Hydrophobic interactions ( $\mathrm{C} \cdots \mathrm{C}$ and $\mathrm{C} \cdots \mathrm{H}$ contacts) are also observed; but features in fingerprint indicate that the spatial arrangement is not stabilized by $\pi \cdots \pi$ interactions. Added to this, the low contact density $\mathrm{N} \cdots \mathrm{H}$ $(6.8 \%)$ and $\mathrm{C} \cdots \mathrm{O}(2,5 \%)$ confirms the absence of such interactions in NPT-HI.

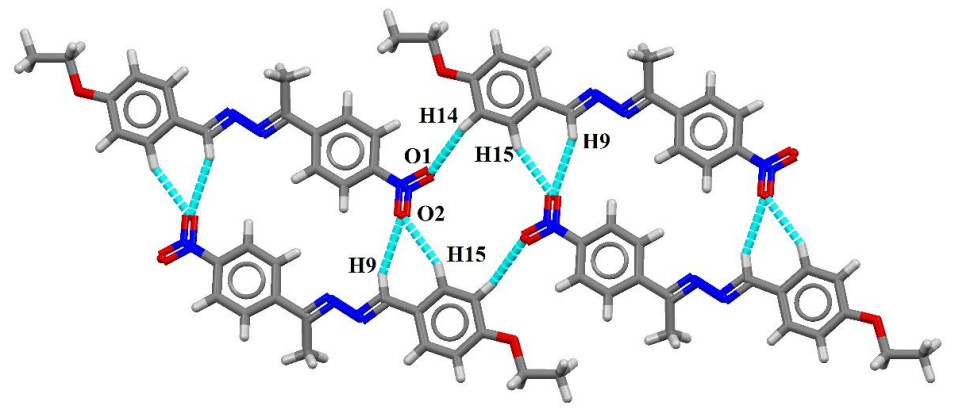

(a)

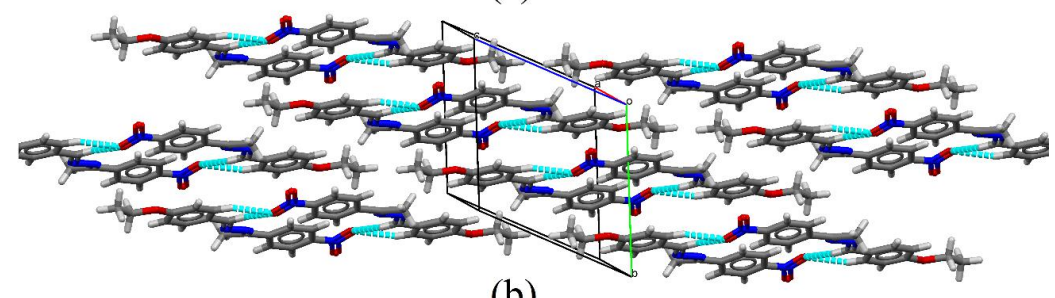

(b)

Fig.1: Representation of part of layer formed by $\mathrm{C} 15-\mathrm{H} 15 \cdots \mathrm{O} 2, \mathrm{C} 9-\mathrm{H} 9 \cdots \mathrm{O} 2$ and

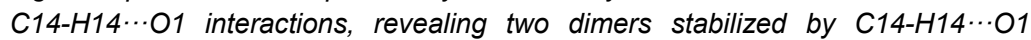
interaction (a) and crystal packing of NPT-HI (b). 